\title{
A robótica na escola como postura pedagógica interdisciplinar: o futuro chegou para a Educação Básica?
}

\author{
Title: Robotics at school as an interdisciplinary teaching approach in Basic Education: The \\ future has arrived to school?
}

Deise Aparecida Peralta

Universidade Estadual Paulista (UNESP),

Faculdade de Engenharia,Ilha Solteira

Departamento de Matemática

deise@mat.feis.unesp.br

\author{
Eduardo Cortez Guimarães \\ Universidade Estadual Paulista (UNESP), \\ Faculdade de Engenharia,Ilha Solteira \\ eduardocortez34@gmail.com
}

\begin{abstract}
Resumo
Este artigo refere-se à investigação norteada pela proposição da robótica como constituinte de prática pedagógica interdisciplinar alternativa ao ensino tradicional de conteúdos curriculares. Admitindo que a robótica na escola tem o potencial de tornar o aluno produtor e não apenas consumidor de tecnologia digital, e o professor protagonista em processos de (re) construção da própria prática, o objetivo é avaliar a possibilidade da robótica na escola se apresentar, não como mais uma ação estratégica de instrumentação, mas como uma oportunidade de interação com a tecnologia numa relação de construção e reconstrução de práticas. A pesquisa contou com um levantamento bibliográfico e também com um levantamento de campo obtido através de vivência na escola e relatos dos professores. Os dados obtidos permitem afirmar que a robótica na escola pode ser aceita como prática interdisciplinar.
\end{abstract}

Palavras-Chave: Robótica. Interdisciplinaridade. Formação de Professores.

\begin{abstract}
This article refers to research guided by the proposition of educational robotics as pedagogical interdisciplinary practical alternative constituent to traditional teaching curricula. Admitting that educational robotics has the potential to make the student producers and not just consumers of digital technology, and the teacher protagonist in the processes of (re) of the practice building, the goal is to evaluate the possibility of robotics in school to present, no as another strategic action instrument, but as an opportunity to interact with technology in a list of construction and reconstruction practices. The research included a literature and also with a field survey obtained through experience at school and reports of teachers. The data obtained allow us to state that robotics in school can be accepted as an interdisciplinary practice.
\end{abstract}

Keywords: Robotics. Interdisciplinarity. Teacher training

Cite as: Peralta, D. A., \& Guimarães, E. C. (2018). Robotics at school as an interdisciplinary teaching approach in Basic Education: The future has arrived to school? (A robótica na escola como postura pedagógica interdisciplinar: o futuro chegou para a Educação Básica?). Brazilian Journal of Computers in Education (Revista Brasileira de Informática na Educação - RBIE), 26(1), 30-50. DOI: 10.5753/RBIE.2018.26.01.30 


\section{Introdução}

Este artigo descreve resultados de uma das investigações que constituem um projeto fomentado pela Fundação de Amparo à Pesquisa do Estado de São Paulo (FAPESP) cujo intuito é estudar potencialidades da robótica na escola.

Desde as famosas publicações de Isaac Asimov (1920-1992), atividades envolvendo robótica e mecatrônica, frequentemente, são relacionadas à contextos futuristas. Apesar do referido autor ter se dedicado a escrever obras de ficção científica, notadamente, alguns cenários culturais e sociais descritos se assemelham aos contemporâneos. Nesse sentido, dentre tantas possibilidades de convites a ações de reflexão, seria possível relacionar a presença da robótica na escola à práticas esperadas no cenário educacional em algum momento caracterizado como futuro?

A expressão robótica na escola, usada neste texto, refere-se à prática em contextos educacionais, geralmente em ambientes escolares, envolvendo a atividade de construção, manipulação e programação de robôs, proporcionando um ambiente de aprendizagem com fomento ao raciocínio, à criatividade, à construção de conhecimento em diferentes áreas e à experiência de conviver em grupos. Como afirma Papert (2008), a robótica na escola serve de plataforma para fazer conexões entre áreas de conhecimento numa estrita relação com o conceito de interdisciplinaridade estabelecido por Fazenda (1994). Papert (2008), investigou recursos que ajudassem alunos a pensar, ou objetos para pensar com, ou seja, objetos concretos que estimulassem a criança a pensar sobre o pensar e, dessa forma, testar hipóteses através da exteriorização das mesmas. O pesquisador dedicou-se, então, a criar uma linguagem de programação na qual crianças "ensinavam" os computadores, afirmando que a educação seria potencializada com a possibilidade de alunos "ensinando" (programando) máquinas (computadores). Resnick (1996) trabalhando em grupo de pesquisas do Massachusetts Institute of Technology (MIT) e aprimorou a ideia de Papert (2008), criando uma de programação adaptada para movimentar pequenos blocos plásticos, sensores a partir de uma programação simples, a ideia era possibilitar a construção de objetos para "um pensar com".

Segundo Silva (2009), a utilização da robótica em contexto educacional tem aumentado no Brasil em função da ampliação das tecnologias disponíveis, da redução dos custos e sobretudo pelas pesquisas científicas, com objetivos e alcances diversos, que vêm sendo desenvolvidas. Lessa et al (2015) afirma que quando analisados os objetivos das pesquisas de robótica em contexto educacional, $62 \%$ dos estudos abordam o uso da robótica para o ensino de conceitos de programação/robótica. $\mathrm{O}$ ensino de conteúdos curriculares através da programação/robótica é objetivo de $17 \%$ dos estudos. Formação de professores e projetos visando a acessibilidade econômica para o uso de robótica representam cerca de $12 \%$ e $9 \%$, respectivamente.

A presença de robótica na escola tem se apresentado como mudança no paradigma de ensino em diversas pesquisas, (Rusk et al. 2008; Silva, 2009; Fernandes, 2013; Mattos et al., 2015), no entanto, as iniciativas tem se relacionado a aspectos tecnicistas de aplicação de propostas previamente elaboradas e formatadas em contextos educacionais, tendo o professor nesse cenário papel de mero executor de manuais de "kits". Isso é consonante a Francisco Júnior et al. (2010) que, em um levantamento bibliográfico sobre a produção científica na base de dados da CAPES, afirma a existência de uma lacuna em relação a estudos que mostrem pressupostos que justifiquem a robótica em sala de aula para além da instrumentação e do ensino de técnica.

A concepção adotada na pesquisa descrita neste artigo é diferente daquelas, habitualmente, utilizadas na implementação de projetos de robótica em ambiente escolar: um grupo de pessoas decide que conteúdo pode ser modelado e oferece um modelo para o conceito em questão a 
partir de um protótipo de robô ou ainda se atêm a formar para o uso de "kits" com metodologia pré-formatada. No caso do presente trabalho a pretensão é investigar a constituição da robótica na escola como parte integrante da prática docente e não, meramente, um recurso a ser empregado pontualmente. Tendo ainda a vantagem de favorecer postura interdisciplinar diante das condições de ensino de conteúdos curriculares.

Como justificativa podemos aceitar que o imperativo das inovações em todas as áreas do saber, do fazer, do ser e da tecnologia acaba por estabelecer o perfil dos profissionais da Educação. Educadores, como transformadores ativos no processo de aprendizagem dos alunos, precisam estar inseridos então nesse mundo de inovações (Barcelos; Behar \& Passerino, 2010). Com isso, surge a necessidade de formar professores atuantes em contextos informatizados e essa formação deveria contemplar ações que encorajassem e subsidiassem o professor para interagir com tecnologias transformando-a e se transformando continuamente. Estima-se que o domínio de conhecimentos sobre robótica, principalmente, sobre sua natureza concreta possa fornecer condições para o professor criar, avaliar e alterar sua prática em sala de aula, caracterizando a tecnologia não como mais uma ferramenta a ser implementada, mas como constituinte de um fazer pautado em autonomia docente.

Diante do exposto, algumas inquietações surgem: Na visão dos professores, a robótica na escola poderia constituir-se em instrumento que conferiria autonomia e ofereceria possibilidades para condução de aulas? A robótica poderia ser avaliada pelos professores como prática de motivação e interação entre eles e com os alunos, utilizando recursos de programação e montagem de dispositivo de forma simples e intuitiva? Projetos de robótica na escola favorecem um contexto de aula interdisciplinar em que os alunos, através de ação física e mental, pudessem construir hipóteses, testá-las e reconstruí-las, experimentando a posição de alguém que pode construir "através" da tecnologia?

E para tanto, objetivamos descrever e analisar a implementação de um projeto de robótica em uma escola da rede estadual paulista de ensino integral, considerando a constituição de práticas pedagógicas interdisciplinares e a participação ativa dos professores.

\section{Participantes}

Participou deste estudo o corpo docente de uma instituição que integra o Programa de Escola de Tempo Integral da rede estadual paulista. Inicialmente, apenas os professores que ensinam Matemática e que ensinam Ciências seriam convidados a participar, porém como a investigação está inserida dentro do questionamento acerca da possibilidade de proposição da robótica como constituinte de uma postura pedagógica interdisciplinar, então o diálogo entre todas as disciplinas se fez necessário.

Todos os participantes foram mantidos no anonimato (sendo designados apenas por Professor 1, Professor 2, Professor 3) e assinaram um termo de autorização e consentimento de acordo com o Comitê de Ética da UNESP antes da coleta de dados.

\section{Procedimentos Metodológicos: material, método e descrição dos resultados}

Este trabalho está inserido numa abordagem qualitativa (Bogdan \& Biklen, 1994). Os dados desta investigação foram constituídos a partir de um levantamento bibliográfico e um levantamento de campo. 


\subsection{Levantamento Bibliográfico}

Este levantamento foi realizado através de busca na literatura (livros, artigos de periódicos e anais de eventos) sobre robótica e sua relação com o processo de ensino e de aprendizagem, interdisciplinaridade e formação de professores. Utilizamos como chave de busca: "robótica na escola", "formação de professores e tecnologias", "interdisciplinaridade" nos banco de dados: Scielo, no banco de teses e dissertações da CAPES e no GOOGLE Scholar.

Os referidos termos foram buscados em filtros de palavras-chave, título e resumos/resenhas/sinopses (de acordo com a natureza do material). A busca foi feita de forma isolada, ou seja, houve uma busca para "robótica na escola", uma para "formação de professores e tecnologias" e uma outra busca para "interdisciplinaridade". Foram descartados resultados que não se referiam ao contexto educacional.

Dentre os trabalhos acadêmicos encontrados aqueles que se referem a "robótica na escola" podem ser classificados em:

i) Trabalho de Grupos de Pesquisas vinculados a grandes Universidades, como em D'Abreu (2004) que descreve um projeto de parceria entre pesquisadores da UNICAMP (Universidade de Campinas) e UNESP (Universidade Estadual Paulista) com o objetivo de ensino inclusivo de geografia e cartografia, com material de baixo custo, a pessoas com deficiência. Ainda na linha de desenvolvimento de aparatos de robótica de baixo custo, a UNICAMP desenvolve, já há tempos, o Projeto Robótica Pedagógica de Baixo Custo (D’Abreu, 1999) que pesquisa bases para programas para robótica em contextos educacionais. O Grupo de Informática Aplicada à Educação (GINAPE) da UFRJ, desde 2008, desenvolve o Laboratório Virtual de Atividades Didáticas em Ciências e Robótica - uma plataforma de acesso a laboratórios remotos, baseada em tecnologias de livre acesso, cujo objetivo principal é o de desenvolver atividades experimentais consonantes a ideia de aprender fazendo (Pinto, 2011).

ii) Aplicação e desenvolvimento de aparatos de robótica como Abrantes (2009), Morelato et al (2010), Pinto (2011), D’ Abreu (2014) e Alves et al. (2014).

iii) Uso de robótica associada a competições como em Cesar (2005) e Zilli (2004).

iv) Busca por soluções livres, incluindo softwares abertos e uso de sucatas (Albuquerque et al, 2007), em alternativa a produtos comerciais (Cesar, 2013).

v) Proposição de assistência remota para atividades com o professor manipulando remotamente o robô do aluno, facilitando a avaliação e intervenção docente quando necessário ou oferecendo um ambiente de aprendizagem interativo que possibilita o controle e simulação de diversos dispositivos pelo aluno (Stinckwich \& Saidan, 2007; SOUZA et al. 2014).

vi) Ensino de conceitos de lógica de programação e algoritmos e montagem e controle de robôs, através de "kits" comerciais, tem sido explorado por pesquisadores de diferentes formas (Lopes; Fagundes 2006, Lopes et al., 2008, Silva et al., 2008, Benitti et al., 2009; Neto et al., 2015; Oliveira, 2016). Em uma revisão sistemática da literatura, sobre robótica aplicada ao ensino, Almeida \& Netto (2015) identificam que a robótica na escola tem sido utilizada associada, na maioria das vezes, aos "kits" Lego Mindstorms (principalmente) ou ao Arduino. Corroborando tais autores temos Cambruzzi e Souza (2015) que utilizam os "kits" da linha Lego em aulas de lógica de programação para alunos do curso técnico em Informática; Aguiar et al. (2015) que descrevem a experiência pedagógica e o impacto positivo da 
realização do projeto Lego em escolas; Cardoso e Antonello (2015) relatam a experiência de utilização de programação visual e robótica, através de ferramentas de codificação por blocos e "kits" Arduino para alunos ingressantes no curso de Bacharelado de Sistemas da Informação e Fiorio et al. (2014) apresentam uma experiência prática da inserção de "kits" de robótica e seus benefícios como ferramenta educativa em escolas públicas estaduais participantes do PIBID (Programa Institucional de Bolsa de Iniciação à Docência) da UTFPR (Universidade Tecnológica Federal do Paraná).

vii) Uso por crianças pequenas, como em Raabe et al. (2015) que relatam a experiência de uso de brinquedos com possibilidades de programação na Educação Infantil para resolução de problemas que envolvem conceitos matemáticos. Ainda na Educação Infantil temos Ribeiro et al. (2009) que usa robótica em atividades de literatura infantil. Friedrich et al. (2012) propõe uma metodologia, utilizando as tecnologias Logo e Lego Mindstorms, para a ambientação e inserção de lógica de programação para crianças de sete a dez anos de idade. Sulivan e Bers (2016) que propõe uma metodologia de oitos semanas para o uso de robótica da educação infantil e séries iniciais do ensino fundamental.

viii) Uso de tecnologias móveis, seja desenvolvendo plataformas que agregam robôs e smartphones (Reis et al.;2014) ou formando professores para o uso de "kits" de robótica e smartphones em sala de aula da Educação Básica (Trentin et al.;2015).

ix) Ensino de conteúdos curriculares como os trabalhos de Petry (1996), Chella (2002), Santos (2005), Miranda (2006), Gonçalves (2007), Labegalini (2007), Fortes (2007), Maliuk,(2009), Furletti, (2010), Gomes (2010), Martins (2012), Santos et al. (2013), Almeida Neto (2014), Almeida (2015), Rodrigues (2015), Santos e Mendonça (2015), Silva et al. (2015), Araújo, (2016), que objetivam a aplicação da robótica a conteúdos e situações específicas, como ensino e aprendizagem de matemática, física e/ou programação de computadores.

x) Discussão de paradigma de Educação Tecnológica, debatendo concepção de sociedade, paradigmas educacionais e a incorporação da robótica na escola como redimensionamento dos processos de ensino e aprendizagem temos autores como Castilho (2002), Ortelan (2003), Zilli (2004), Santos (2004), Rocha (2006), Campos (2005), Castro (2008), Silva (2010), Campos (2011).

Não fora encontrada nenhuma pesquisa, de acordo com o procedimento adotado, que investigasse se a robótica na escola pode se pautar no ideal do professor como capaz de criar condições para (re)contextualizar sua prática e assumir uma postura crítica que possibilite refletir sobre o próprio ato de ensinar, não se adaptando a uma realidade tecnológica e sim mudando concepções que o permita atuar como parte integrante dessa realidade. A maioria mostra que atualmente, a robótica tem adentrado às escolas como uma atividade que pode reunir construção e programação de robôs e pode ser desenvolvida utilizando dispositivos e sensores comercializados no mercado brasileiro ou até mesmo com sucata eletrônica. As atividades são realizadas em uma aula específica, caracterizando a robótica como instrumento, ferramenta ou recurso e não configurando-a a priori como prática interdisciplinar. É possível perceber que já faz algum tempo que vários esforços vêm sendo feitos no sentido de implementar robótica nas escolas. Entretanto, nenhum deles, aparentemente e por falta de literatura (pelo menos que fosse detectada pela nossa revisão) que nos mostre o contrário, registrou os efeitos significativos a que se propôs.

Quanto aos resultados encontrados, referentes a "Interdisciplinaridade", há unanimidade em citar obras da autora Ivani Fazenda, em concordância com suas afirmações, a respeito de 
"Interdisciplinaridade" não possuir sentido único e estável e que, em assim o sendo, torna-se difícil estabelecer uma definição clara e sucinta sobre o tema (Fazenda, 1994). Portanto, devido à falta de delimitação em termos de definição, torna-se importante listar algumas características que esse termo acarreta e que são a ele vinculadas nos resultados encontrados. Primeiramente, há referências à divisão dos termos e o significado de cada parte, temos: Inter $=$ troca, reciprocidade; Disciplina $=$ ensino, ciência. Há também muita referência a interdependência entre as 'diferentes áreas do conhecimento'. No entanto, segundo Fazenda (1994), a maior característica da interdisciplinaridade é a concepção de conhecimento sem a existência de hierarquias, considerando possibilidades de sobreposições e justaposição concomitantes e harmônicas, não sendo uma simples interação entre os conhecimentos de diferentes áreas. Aparentemente, há certo consenso acerca de aspirações por práticas interdisciplinares. Contudo, apesar de ser alvo de muitos estudos, a aquisição de um perfil interdisciplinar pelas escolas parece ser algo difícil e não possível de ser realizado a curto prazo, pois envolve postura coletiva, o estabelecimento de uma cultura de compartilhamento, de diálogo entre os pares. Ribeiro et al. (2009) e Santos e Silveira Júnior (2013) defendem a importância do caráter interdisciplinar em atividades que envolvam robótica na escola, no entanto ainda se prendem ao uso de metodologia formatada previamente e levada "pronta" para os professores executarem.

Nos trabalhos encontrados a partir da busca por "formação de professores e tecnologia", o professor foi considerado o mediador da aprendizagem, tal como confirma revisão efetuada por Abrantes (2009) e a pesquisa desenvolvida por Campos (2011). Sendo a ele atribuído o papel central na criação de condições que levem os alunos a aprenderem e para tanto, de forma geral nos trabalhos encontrados, há indicações de necessidade de formar esses profissionais para o uso de tecnologia (Zilli, 2004; Pinto et al, 2012). Porém, ainda não encontramos trabalhos que se caracterizem por discutir formação de professores para além do domínio e uso técnico da tecnologia nos moldes a que nos propomos.

\subsection{Levantamento de Campo}

O levantamento de campo contou com a imersão dos pesquisadores no ambiente escolar, participando da rotina da escola e entrevistando professores, gestores e alunos. A escola em questão, aqui chamada simplesmente por Escola, fica em um município do interior do Estado de São Paulo.

A Escola passa pela implantação do Programa de Escola de Tempo Integral da Secretaria de Educação do Estado de São Paulo (SEE-SP) e conta no rol das disciplinas eletivas com a Robótica (escrita com letra maiúscula quando representar o nome da disciplina eletiva da Escola).

\subsubsection{Características da Escola e do Programa Escola de Tempo Integral}

A Escola aderiu ao programa de Escola de Tempo Integral do Estado de São Paulo a partir de 2014, mas o modelo de Escola de Tempo Integral começou a ser implantado em 2012 em 16 escolas de Ensino Médio, e expandido, em 2013, para mais 53 unidades, incluindo os anos finais do Ensino Fundamental, em 2014 chegou a 182. Atualmente conta com 257 escolas $^{1}$.

No atual modelo paulista de Escola de Tempo Integral, a jornada é de oito horas e meia no Ensino Fundamental e de nove horas e meia no Ensino Médio, incluindo três refeições diárias. A estrutura conta com salas temáticas de Português, História, Arte e Geografia, além de Salas de Leitura e de Informática.

Na matriz curricular, os alunos têm orientação de estudos, prática de ciências, preparação

\footnotetext{
${ }^{1}$ Segundo dados da Secretaria da Educação do Estado de São Paulo disponível em www.educacao.sp.gov.br/escola-tempo-integral . Acesso em 24 de julho de 2017.
} 
acadêmica e para o mundo do trabalho e auxílio na elaboração de um Plano de Vida que consiste em um projeto para o seu futuro. Além das disciplinas obrigatórias, os estudantes contam também com disciplinas eletivas escolhidas de acordo com o objetivo proposto em seu Plano de Vida. As escolas são responsáveis por oferecer disciplinas eletivas e no caso da Escola foi criada uma eletiva de Robótica. Foi estabelecida uma parceria entre a escola e a Universidade através dos pesquisadores envolvidos no projeto objeto deste artigo.

\subsubsection{Dia a dia na Escola}

Como a proposta é a discussão da constituição de práticas interdisciplinares o delineamento metodológico se fez na interação entre professores de forma conjunta, entendendo que a interdisciplinaridade se constitui na interação, na ação comunicativa, na postura de compartilhamentos, na construção coletiva e no respeito e aceitação do saber das diversas áreas dos agentes que pretendem não romper, mas ir além da disciplinaridade.

Os pesquisadores frequentaram a Escola às terças-feiras e quintas-feiras por três meses consecutivos. Todos os professores foram extremamente colaborativos e mostravam-se prontos a ajudar. Às terças-feiras foram dedicadas a preparação das aulas que seriam dadas na quinta-feira na disciplina eletiva de robótica. Além disso, nas terças-feiras ocorre a Aula de Atividade Pedagógica Coletiva (ATPC) da escola, nesse momento foram realizadas várias observações e conversas/entrevistas com os professores envolvidos nas disciplinas eletivas. Os professores envolvidos concordaram em participar do projeto e assinaram um Termo de Consentimento Livre e Esclarecido (TCLE). Todas as etapas foram registradas em áudio.

\section{Etapa01/Fase01- Discussão e elaboração do delineamento da proposta com professores}

Foram compartilhados conceitos, significados, convergência de objetivos educacionais e de posturas em relação ao uso da robótica na escola. Foram realizados quatro encontros, sendo alguns dos assuntos abordados: O que era entendido por interdisciplinaridade; Opinião sobre o Programa de Escola Integral; Falta de material para ministrar as disciplinas eletivas; Cobranças sofridas pelo professor; Interesse do aluno pela disciplina eletiva; A proposta da robótica como recurso pedagógico ao professor; $\mathrm{O}$ uso de tecnologia na escola e Obstáculos e dificuldades para ministrar as aulas.

\section{Etapa01/Fase 02- Caracterização da realidade escolar}

Durante dois encontros foram analisadas, conjuntamente -pesquisadores e professores, as características físicas e estruturais do ambiente escolar, dos alunos e dos professores participantes. Os professores falaram da falta generalizada de recursos nas escolas públicas; dos desafios da profissão docente; dos desafios de um trabalho envolvendo robótica com materiais baratos e acessíveis. Cada encontro foi marcado pela tarefa de pensar formas que viabilizassem a implementação de práticas com robótica sem a dependência de metodologias impostas por "kits".

\section{Etapa 02/ Fase 01- Discussão de um modelo de robótica a ser implementado}

Aconteceu a apresentação do programa de computador SuperLogo, desenvolvido por Seymour Papert, para a professora coordenadora e para os professores. Nesse programa seria possível trabalhar figuras geométricas com os alunos e ao mesmo tempo familiarizá-los com o ambiente de programação. Chegou-se à conclusão de que não seria interessante usar o programa SuperLogo, pois era difícil reservar a sala de informática necessária toda semana no horário determinado para a eletiva e, além disso, seria algo muito abstrato para os alunos que esperavam algo mais concreto. 
Com o auxílio da internet, mais precisamente, do site YouTube.com, efetuou-se a procura de robôs fáceis de montar e de baixo custo. Foi montado um robô utilizando motores retirados de controles do videogame PlayStation, fios de cobre, cola quente, cola de isopor, suporte para pilhas, pilhas palitos AA e uma escova. No entanto os robôs não funcionaram como esperado, pois as pilhas não forneceram energia suficiente. Foram feitas outras tentativas com pilhas com diferentes voltagens.

A partir de todas as dificuldades apresentadas, ao se tentar montar robôs com material alternativo, seguiu-se uma série de discussões acerca das potencialidades dos "kits" comerciais. A decisão pela adoção se deu em função de o grupo ter concluído que a robótica na escola é viável, desde que não ofereça dificultadores e complicadores ao trabalho do professor. Os professores levantaram questionamentos sobre ser ou não papel do docente se preocupar com aspectos técnicos de informática e/ou somente com aspectos didáticos e pedagógicos em sala de aula. A título de conclusão o grupo afirmou que o importante não é a presença de "kits" na implementação de robótica na escola, mas o papel que esses exercem na prática docente. Tais "kits" devem estar a serviço de facilitar a prática e nunca de pautá-la. Um kit deve oferecer suporte material ao trabalho intelectual do professor.

Facilitar aqui significa tornar mais fácil algo que é idealizado, planejado, mobilizado, desenvolvido e avaliado pelo professor. Isso é o importante de resguardar: um kit não diz ao professor o que fazer, um "kit" se coloca em favor da prática docente. Assim o sendo, um "kit" comercial de robótica para escolas tem papel coadjuvante num cenário em que a prática docente tem atuação principal.

\section{Etapa 02/ Fase 02- Implementação de uma prática subsidiada pelas potencialidades da robótica}

Nesta fase ocorreu a aplicação das atividades planejadas de acordo com concepções adotadas pelos professores nas fases anteriores. As aulas foram registradas. Ainda não havia consenso quanto aos "kits" a serem adquiridos, assim sendo, pesquisadores e professores decidiram usar "kits" de eletrônica educativa ${ }^{2}$ que a Escola possuía. Durante as aulas a cada grupo foram distribuídos dois "kits" acompanhados dos manuais. Cada grupo era livre para manipulação e montagem do material. Foi proposto aos grupos construírem um robô utilizando o motor presente no kit. As aulas envolvendo o aparato possibilitaram diálogo entre professores e alunos, pois todas as etapas do desenvolvimento de robôs eram discutidas de forma conjunta. Além disso, os alunos tinham que mobilizar conhecimentos de todas as disciplinas, tornando concretas as práticas interdisciplinares na escola.

Em uma das aulas os pesquisadores presenciaram uma discussão em sala pelos alunos sobre razão de terem escolhido a Robótica como disciplina eletiva: mais da metade dos alunos afirmaram que já se interessavam pelo assunto. Isso corrobora o fato da robótica apresentar uma natureza altamente motivadora, facilitando o processo de ensino e aprendizagem. Outro assunto nessa discussão foi a possibilidade de aliar robótica ao ensino regular de conteúdos curriculares: os alunos afirmaram ser uma boa ideia, sendo algo menos abstrato. Os alunos em questão eram do $1^{\circ}, 2^{\circ}$ e $3^{\circ}$ anos do Ensino Médio que demonstraram grande interesse por essas aulas.

Com o uso do aparato foi possível notar uma participação ativa dos alunos, bem como uma postura de enfrentamento a problemas. Eles se divertiam montando os robôs, mas ao mesmo tempo levantavam hipóteses sobre o que aconteceu, argumentavam sobre como compreendiam o que estavam acontecendo, confrontavam conteúdos específicos das diversas áreas, explicavam fenômenos e princípios científicos envolvidos. Foi constatado a possibilidade

\footnotetext{
${ }^{2}$ Esta era a denominação encontrada na caixa de um produto composto por sensores, motores e peças de montagens.
} 
de incentivo aos alunos pela atividade investigativa; seja para montar o robô; seja para conectar cabos ou programar o uso de sensores; seja para discutir sobre o conceito físico, químico ou matemático que deveria ser considerado para desenvolver a atividade proposta.

Analisando as falas dos professores, percebe-se que a robótica na escola é uma possibilidade positiva para a sala de aula, podendo se tornar não só uma ferramenta, mas uma prática construída coletivamente, cuja natureza interdisciplinar se configura na articulação de diversos conteúdos em uma mesma atividade.

[...] acredito que possa ser algo muito bom, pois prenderá atenção dos alunos, já que eles gostam do concreto. (PROFESSOR 3)

A robótica desperta muito a atenção dos alunos, ela é um grande atrativo. Os alunos aprendem mais fácil e mostram mais interesse. Aprender através de algo concreto é mais fácil, ver a velocidade de um robô, o tempo gasto para percorrer um espaço, entre outras coisas, transformam a teoria em prática. Além disso, a robótica consegue ser aplicada a diferentes áreas através de atividades montados pelo professor, ou seja, ou seja ela não fica presa a um único conteúdo, estimulando a interdisciplinaridade. (PROFESSOR 1)

Como a robótica pode ser aplicada a diferentes atividades, ela pode ser uma ferramenta que colaborará com a interdisciplinaridade. (PROFESSOR 4)

A partir do momento do uso desse kit, foi possível realizar atividades envolvendo conteúdos teóricos na prática. Então, será um bom recurso ao professor, pois os alunos gostam da robótica e eles mostraram vontade de realizar a atividade. (PROFESSOR 2)

\section{Etapa 03/ Fase 01- Analisando a prática proposta:}

Esta fase se constituiu em espaço para reflexão sobre a efetivação das intenções de ensino e de avaliação planejadas, ou seja, foi uma oportunidade para os professores refletirem sobre a própria prática e se atentar a detalhes que passaram despercebidos na dinâmica das aulas. Durante 04 reuniões na escola, de aproximadamente 1 hora de duração cada, os professores discutiram e elegeram alguns pontos, considerados essenciais, em se tratando da realização de um projeto cujo pilar fosse a interdisciplinaridade. Os professores reconheceram que a robótica na escola seria significativa para a concretização de práticas interdisciplinares se houvesse:

\section{a) Resgate histórico da História e Filosofia da Ciência a partir do uso da robótica.}

Neste processo os alunos naturalmente entram em contato com os conteúdos do Currículo, pois ao reconstituirmos como a Ciência se constituiu entramos em contato com a história de constituição das diversas ciências e o aluno passa a ter ideia que nenhum conhecimento se constrói de forma fragmentada. (PROFESSOR 5)

Ao tratarmos da história, de como se deu o desenvolvimento da Robótica, se depara com todos os processos e revoluções históricos, científicos e culturais pelas quais passaram nossas sociedades. (PROFESSOR 3)

Se estudarmos toda a evolução tecnológica que nos trouxe ao uso de robôs, estudaremos por consequência todas as práticas científicas e sociais que possibilitaram tal evolução. Todo o conhecimento em Exatas, Humanas e Sociais e como ele se desenvolveu através dos tempos. (PROFESSOR 7)

A forma como se desenvolveu a robótica até chegar a escola poderia ser comparado a forma de desenvolvimento do conhecimento de cada área curricular e como eles integram. Ou ainda a própria forma de desenvolvimento do pensamento humano. (PROFESSOR 12) 
Um projeto de robótica pode ser algo concreto que represente a não fragmentação de conhecimento. Para pôr um robô em movimento é preciso mais que conhecimentos de Mecânica é preciso saber relacionar a Mecânica ao mundo real. Para que eu quero um robô andando? Mas ao mesmo tempo valoriza cada conteúdo curricular, afinal se eu quiser por um robô ou mesmo só entender como ele se movimenta ou ainda se eu quiser só falar de movimento preciso saber de mecânica (PROFESSOR 5)

\section{b) Desenvolvimento de aplicações práticas da robótica para resolver/discutir questões de cunho científico e social e atender demandas dos alunos.}

Um projeto a ser desenvolvido conjuntamente e de forma interdisciplinar tem que ter uma cara atual. Afinal, hoje o Currículo para o Ensino Médio pede um aluno que investigue as questões do meio onde vive e que os conteúdos disciplinares seja ferramentas para intervir nesse meio. (PROFESSOR 9)

Apesar de não ser desejável que os alunos pensem que todo conhecimento tem que ter uma utilidade prática logo de cara, algo que se aprende hoje já tem uma aplicação hoje. Nada de propagar o tão famoso pra que serve isso professor, mas seria bem bacana mostrar que conhecimento é uma forma autêntica de operar sobre o mundo das coisas. (PROFESSOR 11)

Acredito que um projeto de robótica com uma temática envolvendo os problemas atuais enfrentados pelo cidadão e que sejam trazidos pelos alunos pode dar uma motivação maior para aprender conteúdos científicos. (PROFESSOR 6)

O interessante é que através de atividade concreta, manipulativa, lúdica os meninos podem se interessar mais em aprender conteúdos científicos que irão ajuda-los a argumentar sobre questões do mundo. (PROFESSOR 8)

Os alunos sentirem-se parte do processo de elaboração do projeto é fundamental. (PROFESSOR 2)

\section{c) Interação entre Robótica e as diversas linguagens das Ciências e da Arte}

Um projeto de robótica pode introduzir o problema da modelagem de comportamento; lembrando que artista cria não apenas forma; mas comportamento, e torna possível situações interativas sem precedentes em espaços físicos ou telemáticos. (PROFESSOR 10)

As diversas linguagens podem ser contempladas em um projeto desta natureza. (PROFESSOR 12)

Talvez seja a oportunidade para os alunos vivenciarem as linguagens expressas sob a forma de arte. Não apenas aquelas que estão diretamente relacionadas conceitualmente como também aquelas que aparecem hibridizadas nas diversas ciências. (PROFESSOR 3)

\section{d) Efetiva e constante comunicação entre os professores}

Pelas nossas discussões entendo que a interdisciplinaridade é um dos imperativos mais importantes das condições de produção de conhecimento científico, exigindo a convergência das diversas ciências. Para que ela ocorra é necessário então que os professores mantenham uma comunicação constante. (PROFESSOR 1).

Um projeto de robótica então deve ser interdisciplinar por natureza, uma vez que para funcionar, além de constituir um campo de produção de discursos que 
interagem com os diversos campos sociais, em especial com o campo científico, a robótica na escola exige que os professores conversem, pois não dá pra cada um dar sua aulinha e pronto. Para se implementar um projeto dessa natureza todos os alunos terão que movimentar todos os conhecimentos aprendidos na escola e ainda contar com o suporte dos professores de cada área. (PROFESSOR 12)

O projeto será coletivo. O professor da disciplina de robótica dará suporte aos meninos no que se refere ao aparato para montagem de robôs, programação essas coisas, mas todos nós em suas aulas tentaremos estabelecer comunicação entre a área predominante de conhecimento de nossas disciplinas e as demais. Só assim os meninos conseguirão desenvolver um projeto, entendendo que conhecimento não se racha, pois terão os conteúdos necessários. (PROFESSOR 8).

\section{Etapa 03/ Fase 02- Planejamento de prática após análise:}

Nesta fase os professores analisaram que tipo de material (aparato para montagem de robôs) seria interessante para o desenvolvimento do projeto na Escola. Para tanto, usaram como referência um artigo de pesquisadores da UNCAMP cujo objetivo principal é analisar alguns "kits" disponíveis no mercado, que eles chamam de robótica pedagógica, segundo suas facilidades e dificuldades de usabilidade (Morelato et al, 2010). Foram usados também para subsidiar a escolha do "kit" conceitos extraídos do livro "Aprendizagem: Linguagem, Comportamento e Cognição", de Charles Catania com tradução da Prof a Dra. Deisy das Graças de Souza (UFSCAR), do livro "Alfabetização Cientifica: Questões e Desafios para a Educação”, de Attico Chassot e do clássico "A máquina das crianças" de Seymor Papert. Foi feita opção pelo uso de um "kit" de robótica relatado em Morelato et al (2010) como o que apresentava peças de montagem resistentes, ambiente de programação em português, com interface de fácil interação, exigência de conceitos básicos compatível com o uso para alunos da educação básica, não exigência da necessidade de acompanhamento de orientador para implementação de projetos, que foi entendido como estímulo à autonomia de alunos e professores. O "kit" escolhido e adquirido foi o Alpha Mecatrônica comercializado pela empresa PETE.

Os professores elegeram o ensino por investigação (Hodson, 1994) como propício para que os estudantes sejam estimulados e encorajados a levantarem e testarem suas hipóteses, indagações e curiosidades, fazendo uso de sua criatividade para transformar a experiência com os "kits" de robótica em um recurso de potencial desenvolvimento de cultura científica. Fizeram ainda um levantamento com os alunos sobre temas que envolvessem questões relevantes para a sociedade que poderiam ser tratados em um projeto e o tema "Poluição" foi o escolhido. Ainda nesta fase os professores se reuniram para discutir os resultados de discussões com os alunos sobre possibilidades para o desenvolvimento de um projeto, as características que deveria ter este projeto e as ações em sala a serem desenvolvidas.

O projeto é da Escola, mas cada turma montou e programou seus robôs, investigando alguma dimensão da temática Poluição, tendo como ferramenta os conteúdos disciplinares previstos no Currículo para sua série. Por exemplo, no $3^{\circ} \mathrm{A}$ os alunos fizeram a opção por investigar o "Efeito Estufa". Construíram um microambiente análogo ao planeta Terra com um sistema de retenção de calor/energia solar, simulando o efeito estufa com montagem e programação de dispositivos robóticos equipados com sensores (de contato, de luz, de temperatura, de cor, de infravermelho, de ruído e de detector de faixas). Para montar todo o aparato os alunos tiveram que mobilizar conteúdos contemplados no Currículo para a $3^{\mathrm{a}}$ série. Os professores desenvolveram o programa de ensino de suas disciplinas promovendo discussões e incentivando a investigação de questões como Energia (conceito, formas, fontes, propagação)X geração de poluentes industrialização X desemprego, emissão e constituição de 
gases $\mathrm{X}$ aquecimento global $\mathrm{X}$ necessidade do planeta se manter aquecido $\mathrm{X}$ mudanças climáticas, recursos naturais $\mathrm{X}$ comportamento de consumo $\mathrm{X}$ economia sustentável, uso de agrotóxicos $\mathrm{X}$ produção de alimentos em larga escala $\mathrm{X}$ aumento da população mundial, políticas econômicas $\mathrm{X}$ políticas ambientais $\mathrm{X}$ relações de poder. Os professores relataram um grande envolvimento dos alunos nas aulas.

Desenvolver o conteúdo programado para a turma, tendo a robótica como aliada, representou um bom avanço nos resultados esperados, pois notei uma grande participação dos alunos, bem como um bom posicionamento frente a problemas científicos e sociais (PROFESSOR 1).

Eles se divertiam montando os robôs, mas ao mesmo tempo levantavam hipóteses sobre o que aconteceu, argumentavam sobre como compreenderam o que estavam acontecendo, confrontando com todo os conteúdos específicos das diversas áreas, explicavam os fenômenos e que princípios da Ciência estariam presentes. (PROFESSOR 12)

Muito importante foi o fato de eles tomarem gosto pela pesquisa seja para montar o robô, como deveriam conectar cabos e programar o uso de sensores, seja sobre o conceito físico, químico ou matemático que deveria ser considerado para ajudar a simular aspectos do efeito estufa. (PROFESSOR 3)

\section{Etapa 04- Avaliação da proposta de robótica na escola como à pratica docente:}

Os professores foram convidados a analisar a proposta, individualmente e também de forma coletiva, sobre dois aspectos: a) robótica como subsídio metodológico que os orientassem a planejar condições de ensino e avaliação de forma interdisciplinar e a interpretar correspondências entre estas práticas e o desempenho dos alunos e b) evidências de impacto nos alunos de aprendizagem de conteúdos curriculares.

Pelo relato dos professores é possível aceitar que as práticas, envolvendo robótica na escola, se revelaram um espaço onde se aprende a construir relações entre conhecimento de diferentes disciplinas, entre as pessoas envolvidas, entre conhecimento escolar e o que acontece fora da escola. Essas relações puderam ser observadas durante o desenvolvimento do projeto e não somente ao final, pois ao empregar determinado conceito o aparato de robótica se comportava de certa forma. Esta forma podia ser avaliada pelos próprios alunos como sendo um resultado adequado ou não. Esse resultado era imediatamente problematizado pelo professor, discutindo com os alunos prováveis hipóteses que explicassem a adequação ou a não adequação do conceito empregado.

Com as atividades do projeto de robótica eu pude ir intervindo com ações que eu acho que posso chamar de ensino ao mesmo tempo em que já observava se aquilo que eu havia ensinado era aplicado pelos alunos na prática. Na verdade era tudo junto: ensinando e avaliando. A robótica favorece isso, pois com o desenvolver do projeto você percebe o que eles aprenderam e o que não aprenderam você já interveem na hora. Não precisa esperar uma atividade específica pra avaliar. (PROFESSOR 1)

Normalmente, a noção de avaliação está na medição de competências e habilidades que o aluno deve exibir a final de um tempo ou de uma sequência de conteúdos Com o projeto de robótica eu não preciso ensinar ...entre aspas...tudo sobre função para depois avaliar se ele consegue modelar o deslocamento de um robô em função de um período de tempo. Ele já vai aplicando na prática e ele mesmo verificando se o conceito está certo ou não. Porque o robô só vai se deslocar o quanto deve se deslocar naquele espaço de tempo se a lei que descreve a função entre as variáveis estiver correta. Dessa forma, eu posso ir ensinando e já avaliando se os conceitos estão sendo aprendidos e são aplicados de forma aceitável. (PROFESSOR 12) 
Tratando ensino e avaliação como indissociáveis, as práticas envolvendo robótica promoveram a inclusão de todos e o desenvolvimento da autonomia e auto direção dos estudantes, com vistas a que participassem como autores de tecnologia. Essa percepção, por parte dos professores, é fundamental para que se possa, no processo pedagógico, orientar o ensino e avaliação para tais finalidades.

\section{Discussão}

A primeira consideração importante a ser feita é sobre a receptividade da proposta. Os professores, alunos e gestores da Escola mostraram imenso respeito e empolgação. A forma como os pesquisadores se colocaram no contexto da instituição, assegurando que a construção seria conjunta, que não se tratava de proposta formatada previamente, de metodologias prontas e/ou testes de produtos provocou nos professores uma reação visível de segurança, ocasionando adesão rápida e aceite de participação na pesquisa. $\mathrm{O}$ mesmo foi evidenciado com os alunos e com a gestão da escola. $\mathrm{O}$ anúncio de respeito à voz da Escola no processo, visivelmente, foi o diferencial na forma de engajamento de todos os envolvidos e provavelmente um dos responsáveis pela mudança de posturas dentro da instituição.

As práticas envolvendo robótica também favoreceram o desenvolvimento de uma cultura interdisciplinar, tendo como exemplo a decisão que a disciplina eletiva fosse coordenada por mais de um professor e eles não precisariam ser, necessariamente, da mesma área ou ministrarem a mesma disciplina. Assim sendo, houve uma grande troca informações sobre disciplinas diferentes. Em diversos momentos foi observada grande discussão entre professores de diferentes áreas sobre como realizar alguma atividade com os robôs em sala de aula. Se tornou forte a presença de comunicação entre os professores.

Para Fazenda (1994), pensar a interdisciplinaridade como junção de disciplinas é pensar o currículo apenas na formação de sua grade, porém, ao se definir interdisciplinaridade como atitude de ousadia e busca frente ao conhecimento, cabe pensar aspectos que envolvem a cultura do lugar onde os professores se formam. Desse modo, somente torna-se possível falar sobre o professor e sua formação para atuar com robótica em contexto educacional quando ampliamos a análise do campo conceitual da interdisciplinaridade. A transposição de certas barreiras, que se apresentam como obstáculos, permite o surgimento de um ensino interdisciplinar, por meio de novos métodos, novos objetivos e de uma nova pedagogia, cuja formulação primeira é a supressão do monólogo e a instauração de uma nova lógica - a dialógica (Fazenda, 1994). Portanto, para que a robótica possa ser parte constituinte da prática docente faz-se necessária a eliminação de barreiras e entre as áreas do conhecimento e de distâncias entre as pessoas que pretendem desenvolvê-la.

O desenvolvimento desta pesquisa mostrou que a robótica na escola pode ter um caráter de prática pedagógica interdisciplinar se o professor for formado, para pensar a própria ação, para além de manuais e guias e para muito mais além da individualidade. É possível afirmar, em consonância com os dados coletados que validam os objetivos pretendidos, que toda proposição de práticas, recursos ou materiais pedagógicos seria mais efetiva se os professores fossem envolvidos, num processo de desenvolvimento da autonomia racional, através da construção coletiva de suas compreensões de mundo e de práticas pedagógicas. Em outros termos, as proposições seriam aceitas e legitimadas pelos professores caso fossem implementadas por meio de ações que os considerassem protagonistas de processos de ensino e não meros executores. No caso da robótica na escola, o professor deve ser envolvido em processos formativos que contribuam para a autonomia necessária a realização do trabalho docente sem precisar que lhe digam, a cada semana de planejamento, a cada reunião ou a cada novo curso de formação, pelo resto de sua vida, o que deve fazer na sala de aula. A contribuição máxima desta pesquisa 
consiste em afirmar que propostas são, mais efetivamente, adotadas por professores quando esses são ativos na construção daquelas, participando de escolhas e decisões.

A robótica na escola pode ser aceita como prática interdisciplinar, pois pode ser compreendida como alternativa ao ensino disciplinar baseado na Ciência excessivamente compartimentada. A práticas envolvendo robótica possibilitaram aos alunos e professores um olhar interdisciplinar e a condição de rever seus conceitos, tendo como referência de análise novos conhecimentos adquiridos no intercâmbio com outras disciplinas. Isso, no caso dos professores, sem a necessidade de cursos de capacitação a priori. Professores e alunos, coletivamente, transformaram um "kit" de robótica em suporte à prática pedagógica ao enxergarem nele um eixo articulador de interdisciplinaridade. Ou seja, o uso de "kit" tem a possibilidade de deixa de ser uma simples ferramenta ao fomentar o diálogo entre pares.

Retomando os objetivos deste estudo é possível afirmar, de acordo com os dizeres e fazeres dos professores participantes e no contexto da escola pesquisada, que a adoção do uso de robótica na escola se constituiu em subsídio a práticas interdisciplinares. Aparentemente, ainda é possível afirmar que as características de um projeto de robótica têm o potencial de alterar práticas pedagógicas, favorecendo a constituição de postura interdisciplinar entre os professores. O projeto de robótica desenvolvido no estudo exigiu que os professores dialogassem dentro da escola. Os professores das diversas disciplinas precisaram trocar conhecimentos e experiências para que o projeto viesse a ter sucesso. Os alunos envolvidos precisaram mobilizar os conhecimentos adquiridos com as diversas ciências para adotar a postura exigida por um projeto de robótica compatível com um conceito de fazer ciência.

Durante o desenvolvimento das atividades envolvendo robótica puderam ser observadas práticas que revelaram um processo muito voltado ao acompanhamento das aprendizagens e desenvolvimento dos estudantes, ou seja, uma avaliação incorporada ao cotidiano, planejamento diário e às ações com intenções de ensino. Os professores, de um modo geral, não desvincularam práticas de ensino de práticas de avaliação. Isto posto uma vez que exerceram uma avaliação contínua, pois ao mesmo tempo em que apresentavam novos conteúdos, intervinham quando conceitos e procedimentos eram empregados de forma não conveniente em determinado momento do projeto. A avaliação era parte do ensino e o ensino parte da avaliação e ambos eram dimensões de um processo mobilizado para desenvolver aprendizagens. Processo este desvinculado da necessidade de ranqueamentos, classificações, pontuações com indicadores numéricos ou de outra ordem, primando pela lógica da inclusão ao oferecer a oportunidade para que todos os alunos participassem do projeto.

Parece possível afirmar então que a robótica na escola pode se pautar no ideal de que o professor é capaz de criar condições para (re)contextualizar sua prática e assumir uma postura crítica. Postura essa que possibilite refletir sobre o próprio ato de ensinar, não se adaptando a uma realidade tecnológica e sim mudando concepções que o permitam atuar como parte integrante dessa realidade. Pela fala dos professores é possível admitir o potencial de tornar o aluno produtor, e não, apenas, consumidor de tecnologia digital, pois construção e manipulação de robôs podem servir de plataforma para fazer conexões entre as áreas disciplinares, corroborando o afirmado por (Papert, 2008). Trata-se então de uma oportunidade de interagir com a tecnologia numa relação de autoria.

\section{Conclusão}

Os dados deste estudo mostram relatos de professores avaliando a robótica na escola como prática que trata ensino e avaliação como elementos indissociáveis na execução de projetos, como o afirmado por Fernandes \& Freitas (2007), corroborando potencial metodológico alternativo ao ensino tradicional de conteúdos curriculares na educação Básica. 
Pelos dados obtidos é possível afirmar que a robótica na escola para o professor representa prática para interagir, ensinar e avaliar, promovendo comunicação entre o corpo docente, pois requer a mobilização de conhecimento das diversas áreas disciplinares. Para os alunos representa estimulo à ação física e mental; pois, através da montagem e manipulação de robôs, podem construir hipóteses, testá-las e reconstrui-las imediatamente experimentando a posição de alguém que pode construir "através" da tecnologia (Valente, 1993). A robótica no ambiente escolar supera, sem romper, com a disciplinaridade, promovendo postura interdisciplinar e fomento à responsabilidade coletiva e particular.

Se o que se espera para uma escola no futuro é que se possa aprender para além de papel e lousa, aula expositiva, provas objetivas e posturas disciplinares. Então, sim, com práticas envolvendo robótica na escola, o futuro já chegou e urge que se fala presente.

\section{Agradecimentos}

À Fundação de Amparo à Pesquisa do Estado de São Paulo (FAPESP) pelo financiamento (Proc 15/26166-8 e Proc e 13/21375-2).

\section{REFERÊNCIAS}

Abrantes, P. C. R. (2009). Aprender com robots. Dissertação de Mestrado, Universidade Católica de Portugal, Lisboa. $\quad$ Disponível http://repositorio.ul.pt/bitstream/10451/3646/1/ulfc055872_tm_Paula_Abrantes.pdf [GS $\underline{\text { Searchl }}$

Aguiar, Y. Q., MacieL, B. K., Matos, S. D. G., Soares, L. B.\& Oliveira, V. M. (2015). Introdução à Robótica e Estímulo à Lógica de Programação no Ensino Básico Utilizando o Kit Educativo LEGO ${ }^{\circledR}$ Mindstorms. Anais dos Workshops do Congresso Brasileiro de Informática na Educação CBIE 2015, (PP. 1418-1424), Maceió. doi: $\underline{10.5753 / \text { cbie.wcbie.2015.1418 [GS Search] }}$

Albuquerque, A. P., Melo, C. M., César, D. R. \& Mill, D. (2007). Robótica Pedagógica livre: instrumento de criação, reflexão e inclusão sócio digital. Anais do Simpósio Brasileiro de Informática na Educação SBIE 2007, (PP. 316-319, São Paulo. Disponível em http://www.br-ie.org/pub/index.php/sbie/article/view/682/ [GS Search]

Almeida Neto, C. A. (2014). O uso da robótica educativa e o desenvolvimento de competências $e$ habilidades matemáticas. Dissertação de Mestrado, Universidade Federal do Ceará, Juazeiro do Norte. Disponível em http://www.repositorio.ufc.br/handle/riufc/8832 [GS $\underline{\text { Search] }}$

Almeida, C. M. S. (2015). A importância da aprendizagem da robótica no desenvolvimento do pensamento computacional: um estudo com alunos do $4^{\circ}$ ano. Dissertação de Mestrado, Universidade de Lisboa, Lisboa. Disponível em http://repositorio.ul.pt/handle/10451/22412 [GS Search]

Almeida, T. O. \& Netto, J. F. M. (2015). Robótica Pedagógica Aplicada ao Ensino de Programação: Uma Revisão Sistemática da Literatura. Anais do Simpósio Brasileiro de Informática na Educação SBIE 2015, (PP. 597-606), Maceió. doi: 10.5753/cbie.sbie.2015.597 [GS Search] 
Alves, R. M.; Sampaio, F. F. \& Elia, M. F. (2014). Duinoblocks: Desenho e Implementação de um Ambiente de Programação Visual para Robótica Educacional. Anais dos Workshops do Congresso Brasileiro de Informática na Educação CBIE 2014, (PP.11-20), Dourados. Disponível em http://www.br-ie.org/pub/index.php/wcbie/article/view/3167 [GS Search]

Araújo, T. M. S. (2016). Práticas de ensino de matemática com a utilização da robótica educacional. Trabalho de Conclusão de Curso, Universidade Federal Rural do Semiárido, Mossoró. Disponível em https://pensare.ufersa.edu.br/tcc/

Barcelos, G. T. B.; Behar, P. A. \& Passerino, L. M. (2010). Integração de Tecnologias Digitais à Pratica Docente de Professores de Matemática: em busca de um modelo de formação continuada. Anais do Congreso Internacional de Informática Educativa -20 años, (PP. ), Bogotá.

Disponível em http://www.ribiecol.org/embebidas/estado_del_arte_2010/animacion.html [GS Search]

Benitti, F. B. V., Vahldick, A., Urban, D. L., Krueger, M. L. \& Halma, A. (2009). Experimentação com Robótica Educativa no Ensino Médio: ambiente, atividades e resultados. Anais do XXVII Congresso da SBC - XV Workshop de Informática na Escola, (PP. 1811-1820), Bento Gonçalves. Disponível em http://www.brie.org/pub/index.php/wie/article/view/2166 [GS Search]

Bogdan, R. C. \& Biklen, S. K. (1994). A investigação qualitativa em educação: uma introdução à teoria e aos métodos. Porto: Porto Editora. [GS Search]

Cambruzzi, E. \& Souza, R. M. (2015). Robótica Educativa na aprendizagem de lógica de programação: aplicação e análise. Anais do XXI Workshop de Informática na Escola WIE 2015, (PP. 21-28), Maceió. doi: 10.5753/cbie.wie.2015.21 [GS Search]

Campos, F. R. (2011). Currículo, Tecnologias e Robótica na Educação Básica. Tese de Doutorado, Pontifícia Universidade Católica de São Paulo, São Paulo. Disponível em https://sapientia.pucsp.br/handle/handle/9619 [GS Search]

Campos, F. R. (2005). Robótica Pedagógica e inovação educacional: uma experiência no uso de novas tecnologias na sala de aula. Dissertação de Mestrado, Universidade Presbiteriana Mackenzie, São Paulo. [GS Search]

Cardoso, R. E \& Antonello, S. L. (2015). Interdisciplinaridade, programação visual e robótica educacional: relato de experiência sobre o ensino inicial de programação. Anais dos Workshops do Congresso Brasileiro de Informática na Educação CBIE 2015, (PP. 12551262). Maceió. doi: 10.5753/cbie.wcbie.2015.1255 [GS Search]

Castilho, M. I. Robótica na Educação: com que objetivos? (2002). Monografia de especialização, Universidade Federal do Rio Grande do Sul, Porto Alegre. [GS Seaarch]

Castro, V. G. (2008). RoboEduc: Uma especificação de um software educacional para ensino da robótica às crianças como uma ferramenta de inclusão digital. Dissertação de Mestrado, Universidade Federal do Rio Grande do Norte, Natal. Disponível em https://repositorio.ufrn.br/jspui/handle/123456789/15217 [GS Search]

Cesar, D. R. (2013). Robótica pedagógica livre: uma alternativa metodológica para emancipação sócio digital e a democratização do conhecimento. Tese de Doutorado, Universidade Federal da Bahia, Salvador. Disponível em 


\section{https://repositorio.ufba.br/ri/handle/ri/16087 [GS Search]}

Chella, M. T. (2002). Ambiente de robótica para aplicações educacionais com o Super Logo. Dissertação de Mestrado, Universidade Estadual de Campinas, Campinas. Disponível em http://bdtd.ibict.br/vufind/Record/CAMP_0dd8bdf3682f2004f2f41a839f640440 [GS $\underline{\text { Scholar] }}$

D’Abreu, J. V. V. (2004). Disseminação da robótica pedagógica em diferentes níveis de ensino. Revista Educativa, Nova Odessa, 1(1), 11-16. [GS Search]

D’Abreu, J. V. V. (1999). Desenvolvimento de ambientes de aprendizagem baseados no uso de dispositivos robóticos. Anais do Simpósio Brasileiro de Informática na Educação SBIE 99, (PP.), Curitiba. $\quad$ Disponível em http://www.conhecer.org.br/download/cp/NOVAS\%20TECNOLOGIAS/M1/leitura\%20ane xa\%204.pdf [GS Search]

D'Abreu, J. V. (2014). Robótica Pedagógica: percurso e perspectivas. Anais do Workshop de Robótica Educacional WRE 2014, (PP. 79-83), São Carlos. Disponível em http://www.natalnet.br/wre2014/Anais_WRE2014.pdf\#page=79 [GS Search]

Fazenda, I. C. A. (2013). Interdisciplinaridade: história, teoria e pesquisa. 4.ed. Campinas: Papirus. [GS Search]

Fernandes, C. C. (2013) S-educ: Um simulador de ambiente de robótica educacional em plataforma virtual. Dissertação de Mestrado, Universidade Federal do Rio Grande do Norte, Natal. Disponível em http://bdtd.ibict.br/vufind/Record/UFRN_8efe7a739f7418604cd33655e8251ead $\quad$ [GS $\underline{\text { Search] }}$

Fernandes, C. O. \& Freitas, L. C. (2007). Indagações sobre currículo: currículo e avaliação. Brasília: $\mathrm{MEC} / \mathrm{SEB}$.

Disponível

em http://portal.mec.gov.br/seb/arquivos/pdf/Ensfund/indag5.pdf [GS search]

Fortes, R. M. (2007). Interpretação de gráficos de velocidade em um ambiente robótico. Dissertação de Mestrado, Pontifícia Universidade Católica de São Paulo, São Paulo. Disponível em https://sapientia.pucsp.br/handle/handle/11132 [GS Search]

Francisco Júnior, N. M.; Vasques, C. K. \& Francisco, T. H. (2010). A Robótica Educacional e a Produção Científica na Base de Dados da CAPES. Revista Electrónica de Investigación y Docência (REID), 4 (Julho), 35-53, Jaén. Disponível em http://www.ujaen.es/revista/reid/revista/n4/REID4art2.pdf [GS Search]

Friedrich, R. V.;Santos, D. S.;Santos K., R.; Puntel, M. D. \& Biasoli, D. (2012). Proposta metodológica para a inserção ao ensino de lógica de programação com logo e lego mindstorms. Anais do Simpósio Brasileiro de Informática na Educação SBIE 2012, (PP.), Rio de Janeiro. Disponível em http://www.br-ie.org/pub/index.php/sbie/article/view/1762 [GS Search]

Furletti, S. (2010). Exploração de tópicos de matemática em modelos robóticos com utilização do software Slogo no ensino médio. Dissertação de Mestrado, Universidade Pontifícia Católica de Minas Gerais, Belo Horizonte. Disponível em http://www.biblioteca.pucminas.br/teses/Informatica_FurlettiS 1.pdf [GS Search] 
Gomes, C. G., Silva, F. O., Botelho, J. C., \& Souza, A. R. (2010). A Robótica como facilitadora do Processo Ensino-aprendizagem de Matemática no ensino Fundamental. Ensino de Ciências e Matemática IV-Temas e Investigações. São Paulo: Editora UNESP Cultura Acadêmica. Disponível em http://books.scielo.org/id/bpkng/pdf/pirola-978857983081511.pdf [GS Search]

Gonçalves, P. C. (2007). Protótipo de um robô móvel de baixo custo para uso educacional. Dissertação de Mestrado, Universidade Estadual de Maringá, Maringá. Disponível em https://repositorio.ufba.br/ri/handle/ri/18614 [GS Search]

Hodson, D. (1994). Hacia un enfoque más crítico del trabajo de laboratorio. Enseñanza de las Ciencias, 12(3), 299-313. Barcelona. Disponível em http://www.raco.cat/index.php/ensenanza/article/viewFile/21370/93326 [GS Search]

Labegalini, A. C. (2007). A construção da prática pedagógica do professor: o uso do Lego/Robótica na sala de aula. Dissertação de Mestrado, Pontifícia Universidade Católica do Paraná, Curitiba. Disponível em http://bdtd.ibict.br/vufind/Record/P_PR_9d2b7c4d893f41da16761cbc3cd6e913/Details [GS $\underline{\text { Search] }}$

Lessa, V.; Forigo, F.; Teixeira, A. \& Licks, G. P. (2015). Programação de Computadores e Robótica Educativa na Escola: tendências evidenciadas nas produções do Workshop de Informática na Escola. Anais do XXI Workshop de Informática na Escola WIE 2015, (PP. 92-101), Maceió. doi: 10.5753/cbie.wie.2015.92 [GS Search]

Lopes, D. Q. \& Fagundes, L. C. (2006). As Construções Microgeneticas e o Design em Robótica Educacional. Revista Novas Tecnologias na Educação RENOTE, 4(2), Porto Alegre. Disponível em http://seer.ufrgs.br/index.php/renote/article/view/14150/8085 [GS Search]

Lopes, D. Q., Fagundes, L. C. \& Biazus, M. C. (2008). Robótica Educacional: técnica e criatividade no contexto do projeto Um Computador por Aluno. Anais do XIX Simpósio Brasileiro de Informática na Educação SBIE 2008, (PP. 623-633), Porto Alegre. Disponível em http://www.br-ie.org/pub/index.php/sbie/article/view/751 [GS Search]

Maliuk, K. D. (2009). Robótica educacional como cenário investigativo nas aulas de matemática. Dissertação de Mestrado, Universidade Federal do Rio Grande do Sul, Porto Alegre. Disponível em http://www.lume.ufrgs.br/handle/10183/17426 [GS Search]

Martins, E. F. (2012). Robótica na sala de aula: os estudantes aprendem matemática? Dissertação de Mestrado, Universidade Federal do Rio Grande do Sul, Porto Alegre. Disponível em http://www.lume.ufrgs.br/handle/10183/69934 [GS Search]

Mattos, S. D. G et al. (2015). Introdução à robótica e estímulo à lógica de programação no ensino básico utilizando o kit educativo LEGO ${ }^{\circledR}$ Mindstorms. Anais dos Workshops do Congresso Brasileiro de Informática na Educação CBIE 2015, (PP. 1418-1424), Maceió.

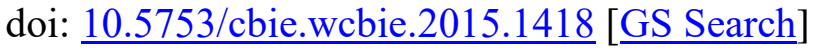

Miranda, G. L. (2007). Limites e possibilidades das TIC na educação. Sísifo: Revista de Ciências da Educação, 3, Lisboa. [GS Search]

Morelato, L.A; Nascimento, R. A. O.; Abreu, J. \& Borges; M. A. F. (2010). Avaliando diferentes possibilidades de uso da robótica na educação. REnCiMa Revista de Ensino de 
Ciências $\quad e \quad$ Matemática,1(2), São Paulo. Disponível em http://revistapos.cruzeirodosul.edu.br/index.php/rencima/article/view/11 [GS Search]

Neto, R. P. B., Rocha, D. P., Santana, A. M. \& Souza, A. A. S. (2015). Robótica na educação: uma revisão sistemática dos últimos 10 anos. Anais do XXVI Simpósio Brasileiro de Informática na Educação SBIE 2015, (PP.386-393), Maceió. doi: $\underline{10.5753 / \text { cbie.sbie.2015.386 [GS Search] }}$

Ortelan, I.T. (2003). Robótica Educacional: Uma Experiência Construtiva. Dissertação de Mestrado, Universidade Federal de Santa Catarina, Florianópolis. Disponível em https://repositorio.ufsc.br/handle/123456789/85322 [GS Search]

Papert, S. (2008). A Máquina das Crianças: repensando a escola na era da informática. Porto Alegre: Artmed. [GS Search]

Petry, P. P. (1996). Processos cognitivos de professores num ambiente construtivista de robótica educacional. Dissertação de Mestrado em Psicologia, Universidade Federal do Rio Grande do Sul, Porto Alegre. [GS Search]

Pinto, M. C. (2011). Aplicação de arquitetura pedagógica em curso de robótica educacional com hardware livre. Dissertação de Mestrado, Universidade Federal do Rio de Janeiro, Rio de Janeiro. Disponível em http://www.nce.ufrj.br/ginape/publicacoes/dissertacoes/d_2011/d_2011_marcos_de_castro. pdf [GS Search]

Pinto, M. D. C., Elia, M. D. F., \& Sampaio, F. F. (2012). Formação de professores em robótica educacional com Hardware Livre Arduino no contexto Um Computador por Aluno. Anais do XVIII Workshop de Informática na Escola WIE 2012, (PP.), Rio de Janeiro. Disponível em http://www.br-ie.org/pub/index.php/wie/article/view/2100 [GS Search]

Raabe, A., Rodrigues, A. J., Santana, A. M., Vieira, M. V., Rosário, T., \& Carneiro, A. C. R. (2015). Brinquedos de Programar na Educação Infantil: Um estudo de Caso. Anais do Workshop de Informática na Escola WIE 2015, (PP. 42-51), Maceió. doi: $\underline{10.5753 / \text { cbie.wie.2015.42 [GS Search] }}$

Reis, C. A. S; Sarmento, H. R. \& Zaramella, V. (2014). Ferramenta de auxílio ao desenvolvimento do pensamento computacional: uma plataforma robótica controlada por smartphone. Trabalho de Conclusão de Curso, Universidade Tecnológica Federal do Paraná, Curitiba. Disponível em http://repositorio.roca.utfpr.edu.br/jspui/handle/1/2972 [GS Search]

Resnick, M., Martin, F., Sargent, R., \& Silverman, B. (1996). Programmable bricks: Toys to think with. IBM Systems journal, 35(3.4), Riverton. Disponível em http://cs.wellesley.edu/ rds/handouts/ToystoThinkWith.pdf [GS Search]

Ribeiro, C. R., Coutinho, C. P., \& Costa, M. F. (2009). O papel interdisciplinar da robótica nos contos infantis. Actas da VI Conferência Internacional de TIC na Educação, (PP. 179-191), Braga. Disponível em https://repositorium.sdum.uminho.pt/handle/1822/9439 [GS Search]

Rocha, R. (2006). Utilização da Robótica Pedagógica no Processo de Ensino Aprendizagem de Programação de Computadores. Dissertação de Mestrado, Centro Federal de Educação Tecnológica de Minas Gerais, Belo Horizonte. Disponível em http://www.files.scire.net.br/atrio/cefet-mg-ppget upl/THESIS/130/rogerio rocha.pdf [GS 


\section{$\underline{\text { Search] }}$}

Rodrigues, W. S. (2015). Atividades com robótica educacional para aulas de matemática do $6^{\circ}$ ao $9^{\circ}$ ano do ensino fundamental: utilização da metodologia LEGO Zoom Education. Dissertação de Mestrado Profissional, Universidade Estadual Paulista Júlio Mesquita Filho, $\begin{array}{llllll}\text { São José } & \text { do } & \text { Rio } & \text { Preto. } & \text { Disponível } & \text { em }\end{array}$ http://bdtd.ibict.br/vufind/Record/UNSP bbc1e2541025e4e53dca5481a2dc4a02 [GS Serch]

Rusk, N., Resnick, M., Berg, R., \& Pezalla-Granlund, M. (2008). New pathways into robotics: Strategies for broadening participation. Journal of Science Education and Technology, 7(1), New York. $\quad$ Disponível em http://www.legolab.daimi.au.dk/Danish.dir/JanneFLL/NewPathways.pdf [GS Search]

Santos, C. F. (2005). Um estudo sobre robótica educacional usando Lego Mindstorm. Dissertação de Mestrado, Universidade Federal do Espírito Santo, Vitória. [GS Search]

Santos, F. F. (2004). A robótica educacional como ambiente para a produção de significados no ensino médio. Dissertação de Mestrado em Educação, Universidade Estácio de Sá, Rio de Janeiro. http://www.estacio.br/mestrado/educacao/dissertacoes/Resumo\%20TICPE Fred\%20Ferreir a $\% 20$ dos $\% 20$ Santos.pdf [GS Search]

Santos, L. S. \& Silveira Junior. C.R. (2013). O ensino interdisciplinar: o uso da robótica educativa nas aulas de matemática do ensino médio. Anais do $V$ Encontro Estadual de Didática e Práticas de Ensino, (PP.), Goiânia. Disponível em http://www2.unucseh.ueg.br/ceped/edipe/anais/vedipefinal/index.php?pg=resumo\#gt05

Santos, M. E., \& Mendonça, A. P. (2015). Aprendendo as relações métricas do triângulo retângulo com robótica: perspectiva do planejamento de ensino. VI Workshop de Robótica Educacional WRE, (PP. 28-33), Uberlândia. Disponível em http://www.natalnet.br/wre2015/wre2015.pdf\#page=27 [GS Search]

Santos, T. N.; Pozzebon, E. \& Frigo, L. B. (2013). A utilização de robótica nas disciplinas da educação básica. Anais do II Simpósio de Integração Científica e Tecnológica do Sul Catarinense SICT - Sul, (PP. 616 -623), Araranguá. Disponível em http://periodicos.ifsc.edu.br/index.php/rtc/article/view/1165/840 [GS Search]

Silva, A. F., Silva, A. A. R. S., Goncalves, L. M. G., Guerreiro, A. M., Dennis, B. A. \& Barros, R. P. (2008). Utilização da Teoria de Vygotsky em Robótica Educativa. Anais do IX Congreso Iberoamericano de Informatica Educativa, (PP.), Caracas. Disponível em http://ribiecol.org/embebidas/congreso/2008/Site/Imagenes/utilizacion_teoria_vygotkski_ro botica.pdf [GS Search]

Silva, A. A. R. S. (2010). Robótica e Educação: uma possibilidade de inserção sócio digital. Dissertação de Mestrado, Universidade Federal do Rio Grande do Norte, Natal. Disponível em http://www.repositorio.ufrn.br:8080/jspui/handle/123456789/14394 [GS Search]

Silva, A. F. (2009). RoboEduc: Uma Metodologia de Aprendizado com Robótica Educacional. Tese de Doutorado, Universidade Federal do Rio Grande do Norte, Natal. Disponível em http://bdtd.ibict.br/vufind/Record/UFRN_4bcd04ffbf53622ac518c0cf0bea42d7 [GS Search] 
Silva, H. R., Silva, S. F. \& Silva, J. R. (2015). Robótica e Matemática na Formação da Cidadania: Associando Números Negativos e Educação no Trânsito. VI Workshop de Robótica Educacional WRE 2015, (PP. 10-15), Uberlândia. Disponível em http://www.natalnet.br/wre2015/wre2015.pdf [GS search]

Souza, P. R. A., Sampaio, F. F., Elia, M. F., \& Brandão, S. (2014). LabVad: Laboratório Remoto para o Desenvolvimento de Atividades Didáticas com Robótica. XX Congresso Internacional de Informática Educativa TISE 2014, (PP. 690-694), Fortaleza. Disponível em http://www.tise.cl/volumen10/TISE2014/tise2014 submission 218.pdf [GS Search]

Stinckwich, S., Lemaignan, S. \& Saidan, S. (2007). Squeakbot:a pedagogical robotic plataform. Fifth International Conference on Creating, Connecting and Collaborating through Computing, (PP. ), Poitiers. doi: 10.1109/C5.2007.28 [GS Search]

Sullivan, A.\& Bers, M. U. (2016). Robotics in the early childhood classroom: learning outcomes from an 8-week robotics curriculum in pre-kindergarten through second grade. International Journal of Technology and Design Education, 26(1), New York. Disponível em https://ase.tufts.edu/devtech/publications/robotics\%20paper.pdf [GS Search]

TRENTIN, M. A., SIGNOR, L., \& TEIXEIRA, A. C. (2015). Percepções de professores do ensino básico sobre robótica educativa. Revista Tecnologias na Educação, 3(1). Disponível em http://tecedu.pro.br/wp-content/uploads/2015/12/Art8-vol13-dez2015.pdf [GS Search]

VALENTE, J. A. (1993). Computadores e conhecimento: repensando a educação. Campinas: Gráfica Central da UNICAMP. Disponível em http://www.nied.unicamp.br/sites/default/files/livros/livro-computadores-econhecimento.pdf [GS Search]

ZILLI, S. (2004). A Robótica Educacional no Ensino Fundamental: Perspectivas e Prática. Dissertação de Mestrado, Universidade Federal de Santa Catarina, Florianópolis. Disponível em https://repositorio.ufsc.br/handle/123456789/86930 [GS Search] 